PROBLEMS

OF MANAGEMENT

IN THE $21^{\text {st }}$ CENTURY

Volume 7,2013

\title{
DEVELOPING A MODEL TO ENHANCE LABOR PRODUCTIVITY USING BRIDGE CONSTRUCTION BENCHMARK DATA
}

\author{
Seonghoon Kim \\ Georgia Southern University, USA \\ E-mail: shkim@georgiasouthern.edu \\ Yong Bai \\ North Dakota State University, USA \\ E-mail: yong.bai@ndsu.edu
}

\begin{abstract}
The Labor Working Status Monitoring (LWSM) Model that incorporates the WRITE and the industry benchmark data was developed through the five steps to enhance labor producitivty in bridge construction operations. The first step of the development process was to conduct a literature review, followed by the second step which was to develop the WRITE. During the development, the authors identified the necessary hardware and software for the WRITE and outlined a schematic to show the connection of major hardware components. The third step was to develop the LWSM Model for monitoring the on-site construction labor working status by comparing data from the WRITE with the industry benchmark data. A survey methodology was used to acquire industry benchmark data from bridge construction experts. The fourth step was to demonstrate the implementation of the LWSM Model at a bridge construction site. During this phase, labor working status data collected using the WRITE was compared with the benchmark data to form the basis for the project managers and engineers to make efficiency improvement decisions. Finally, research findings and recommendations for future research were outlined. The success of this research made several contributions to the advancement of bridge construction. First, it advances the application of wireless technology in construction management. Second, it provides an advanced technology for project managers and engineers to share labor working status information among project participants. Finally, using the developed technology, project managers and engineers can quickly identify labor efficiency problems and take action to address these problems. .
\end{abstract}

Key words: bridge, benchmark, construction, management, monitoring, productivity, wireless.

\section{Introduction}

Research on determining on-site construction labor working status has been carried out for many years. It is a branch of construction productivity study with an emphasis on determining if the status of a construction worker is effective working, contributory working, or nonworking. Over the years, several techniques have been developed to measure labor working status including stopwatch study, photographic, time-lapse, and others (Fondahl, 1960; Oglesby, Parker, \& Howell, 1989; Seonghoon Kim, 2009). Several researchers have used the video/camera system to automatically track construction processes and resource utilizations and developed computer algorithms to determine on-site construction efficiency or productivity (Gong \& Caldas, 2010; Seonghoon Kim, 2009). 
In the construction industry, the labor working status (LWS) is usually classified into three categories including: effective working, contributory working, and nonworking (Adrian, 2004). Any motion that is essential for progress and that adds to the completion of a construction activity is defined as effective working. Contrarily, any motion that does not add to the completion of a construction activity is termed as non working. Contributory working is defined as any action that is essential for progress, but does not directly add to the completion of a construction activity. The contributory working was not included in the development of the LWSM Model. Industry professionals indicated that it was difficult, if not impossible, to determine the benchmark data for the contributory working at a construction site. This was the main reason that the authors didn't include the contributory working in this study. However, the subject should be studied in future research.

All available measurement methods have two common limitations. First, existing methods do not provide a platform to share the collected data among owner, engineers, contractors, and material suppliers. Thus, communication and coordination among parties involved in the construction operations are not conducted effectively in terms of addressing on-site construction labor efficiency problems (Bai \& Kim, 2007). Second, there is no comprehensive model that could be used to process the collected data, compare the collected data with the industry benchmark data, and utilize the comparison results to make a decision regarding whether the on-site labor performance should be improved or not. As a result, opportunities to address the problems of construction operation efficiency are lost. To overcome these shortfalls, there is a need to develop new technologies to monitor on-site construction labor performance.

The main objective of this research project was to develop the Labor Working Status Monitoring (LWSM) Model for monitoring the labor working status at bridge construction sites by utilizing data collected by the WRITE and benchmarking data gathered from experts in the bridge construction industry. A steel girder bridge reconstruction project over Interstate 70 (I-70) in Kansas was selected for the implementation. The implementation of the LWSM Model was demonstrated in a bridge construction project to show how the LWSM Model could be used by the project managers and engineers to identify on-site labor efficiency problems and to quickly take actions to address these problems.

The research aim was achieved through the following steps. The first step of this research project was to conduct a literature review, followed by the second step which was to develop the WRITE. During the development, the authors identified the necessary hardware and software for the WRITE and outlined a schematic to show the connection of major hardware components. The third phase was to develop the LWSM Model for monitoring the on-site construction labor working status by comparing data from the WRITE with the industry benchmark data. A survey methodology was used to acquire industry benchmark data from bridge construction experts. The fourth phase was to demonstrate the implementation of the LWSM Model at a bridge construction site. During this phase, labor working status data collected using the WRITE was compared with the benchmark data to form the basis for the project managers and engineers to make efficiency improvement decisions. Finally, research conclusions were outlined.

\section{Methodology of Research}

Existing on-site construction productivity measurement methods have some common limitations such as not providing data necessary for engineers and project managers to conduct real-time analyses and to share data with other project participants. To improve the quality of construction schedules, there is a need to develop an advanced productivity measurement system that will overcome mentioned shortfalls. An ideal method for measuring construction productivity should satisfy the following basic criteria: 1) monitoring multiple trades in one job site; 2) simple; 3 ) inexpensive; 4) consistent and identical; 5) not very time consuming; 6) reflective of what actually occurs at the site; and 7) timely so that actions are taken on short durations activities (Noor, 1998; Thomas \& Kramer, 1988). 
PROBLEMS

OF MANAGEMENT

IN THE $21^{\text {st }}$ CENTURY

Volume 7, 2013

The WRITE System has several unique advantages. First, there is no disruption to construction operations. The WRITE System was designed to be effectively used in any field conditions, such as adverse weather conditions, and operated by one person. Second, the onsite construction productivity can be determined in real-time so that the project manager will be able to take action immediately if necessary. Third, the collected data can be shared by all participants in the construction project via the Internet at any time and at any location. Fourth, labor and equipment cost for measuring productivity is relatively inexpensive. Fifth, the system uses videotaping as well as time-lapse video technique so that it can provide an accurate interpretation of a construction operation.

Figure 1 presents the framework of the WRITE System that was developed during the process of this research project. Once the video camera takes pictures from a construction site, the data processor immediately saves the pictorial data into files. Then, these files are transmitted in real-time via a wireless modem. An engineer or a project manager can access the data files via a wireless modem and the IP address at another location to conduct productivity analysis using computer software.

Although the video camera used in the WRITE is similar to a traditional time-lapse video camera, the WRITE is a much advanced system for the following reasons. First, the WRITE transfers data instantly via a wireless network and displays them in a website. As a result, collected data will be available to anyone at the jobsite or at a remote location as long as the person has an Internet connection, and data analysis can be performed immediately without time delay due to transporting the collected data. Thus, actions to address on-site labor efficiency problems could be taken just in time. Second, data analysis results and live pictures can be presented on a website for all project participants. Therefore, communication and cooperation among project participants will be improved. Even if people are physically located at different places, they can view the same images and data analysis results on a computer screen and discuss possible solutions for a problem.

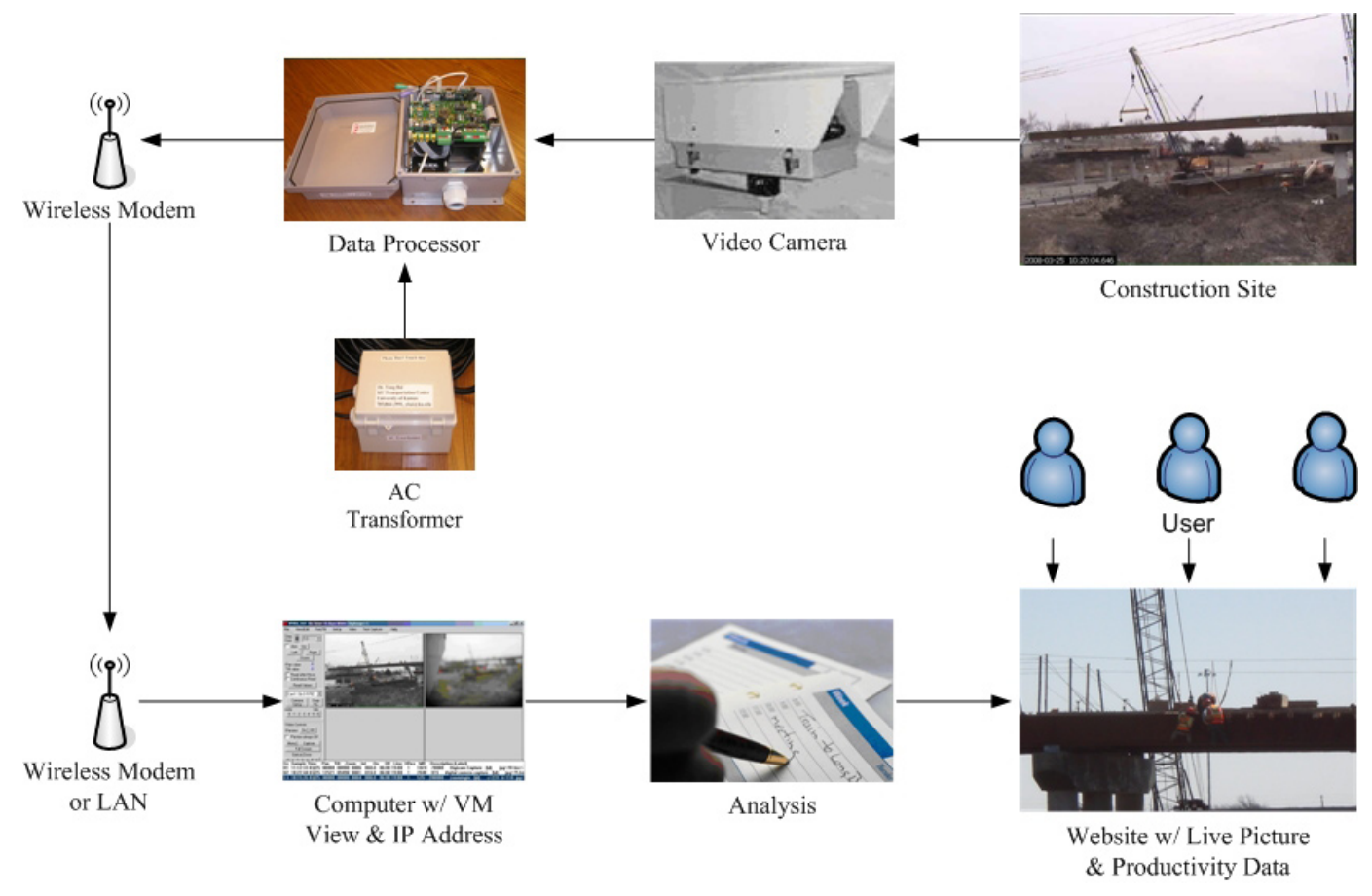

Figure 1: Framework of the WRITE System. 


\section{Development of the LWSM Model}

After building the WRITE, the LWSM Model for monitoring the on-site labor working status was developed as shown in Figure 2. In this model, the first task is to collect pictorial data at a construction site using the WRITE. The second task is to determine the on-site labor working status. The labor working status can be described using the ratio of working time versus total time (working ratio) or the ratio of nonworking time versus total time (nonworking ratio). The working ratio plus the nonworking ratio is equal to one. The third task is to compare the on-site working ratio with the industry benchmark data. With the help from construction industry professionals, the authors classified the benchmark data into two categories including 1) acceptable working ratio, and 2) working ratio at which an action for improvement should be taken immediately. The comparison criteria used by the LWSM Model are presented in Table 1. The industry professionals indicated that multiple decision stages were necessary in the LWSM Model because real-world construction operations were complicated and a problem should be addressed in different ways based on its stage.

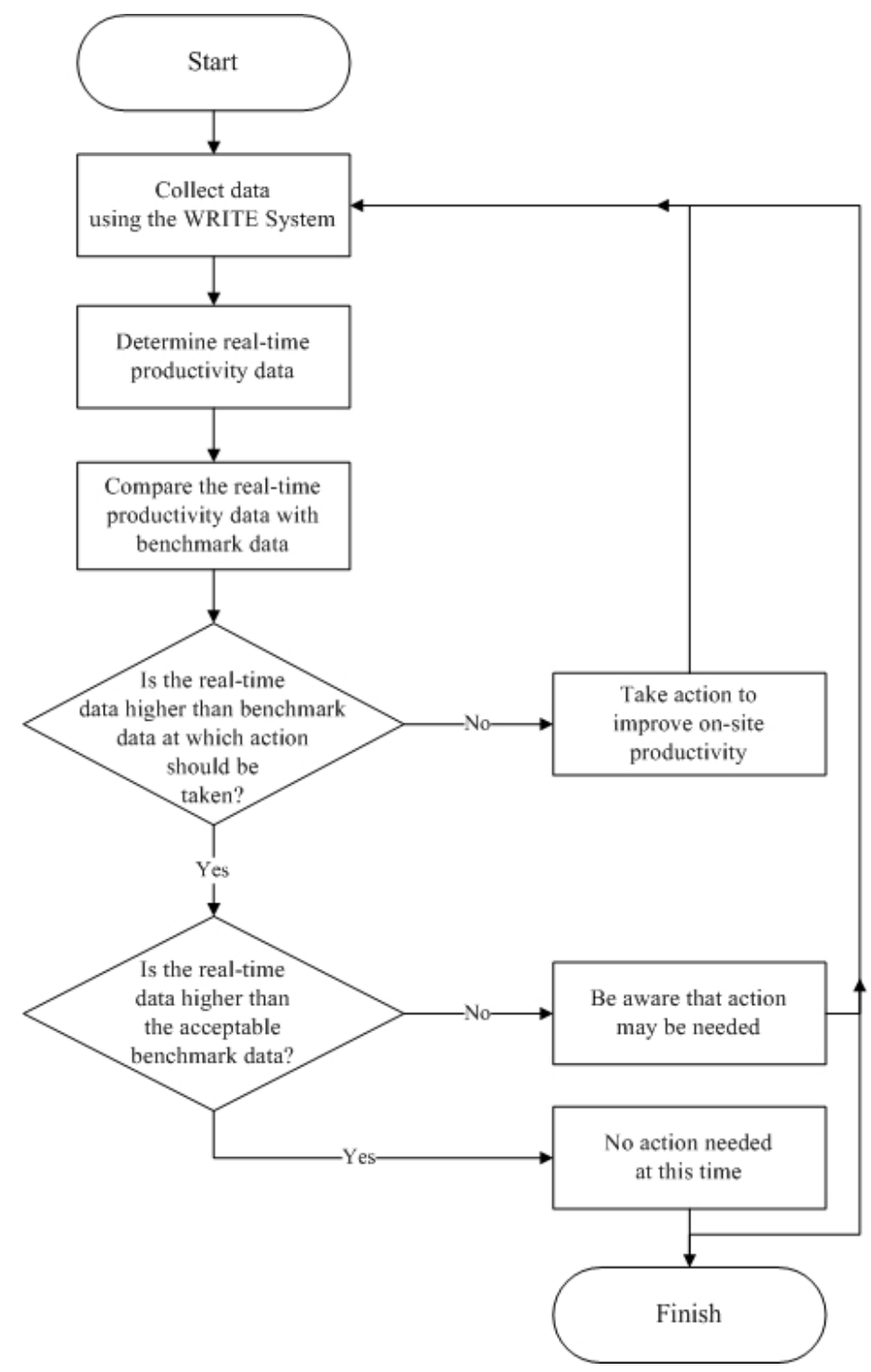

Figure 2: Framework of the LWSM Model. 
Seonghoon KIM, Yong BAI. Developing a Model to Enhance Labor Productivity Using Bridge Construction Benchmark Data

PROBLEMS

OF MANAGEMENT

IN THE $21^{\text {st }}$ CENTURY

Volume 7, 2013

Table 1. Work Breakdown Structure (WBS) for Bridge Reconstruction.

During the comparison, a project manager or an engineer will answer two questions and then make the decision accordingly. The first question is whether the on-site labor working ratio is higher than the benchmark working ratio at which actions on improving efficiency should be taken immediately. If the answer to this question is no, management needs to take actions immediately to improve the on-site construction operations. Examples of actions may include determining whether or not the crew size should be increased or decreased, and whether or not more equipment should be employed. If the answer to the first question is yes, management goes to the next stage to compare the on-site labor working ratio with the benchmark acceptable working ratio. If the onsite working ratio is higher than the acceptable working ratio, no action is needed. Otherwise, management needs to be aware that an action for improving construction operations may be needed in the near future, and close monitoring is necessary at the construction site. The LWSM Model can be utilized for the entire period of construction or for a segment of construction. The uniqueness of the LWSM Model is that it compares the onsite labor working status data with the industry benchmark data and uses the comparison results as a guideline for a project manager or an engineer to make a decision on labor performance improvement.

\section{Implementation of the LWSM Model}

The implementation of the LWSM Model was performed to demonstrate how it could be utilized to monitor on-site labor working status. A steel girder bridge reconstruction project over Interstate 70 in Lawrence, Kansas, was selected because steel girder bridges are the most common short span bridges in the U.S. They feature long-lasting structures, easy construction, and economical cost (Barker \& Puckett, 1997). The Kansas Turnpike Authority (KTA) awarded this 327.8 feet bridge reconstruction project to a contractor for the total price of $\$ 1.9$ million, and the period of construction was about four months from February to June in 2008.

The bridge reconstruction operations interfered with the busy traffic on the I-70, thus, finishing construction on time or ahead of schedule was a high priority. Figure 3 shows the bridge reconstruction site, the WRITE System, and data collection form. Prior to implementation, the authors reviewed plans, specifications, cost, schedule, and other related documents to obtain information on project uniqueness, crew size, and historical daily efficiency. In addition, the authors visited the job site to gather the geographical information in order to develop the implementation plan. Three topics will be described in detail in this section including bridge work breakdown structure, acquiring benchmark data, and implementation results. 

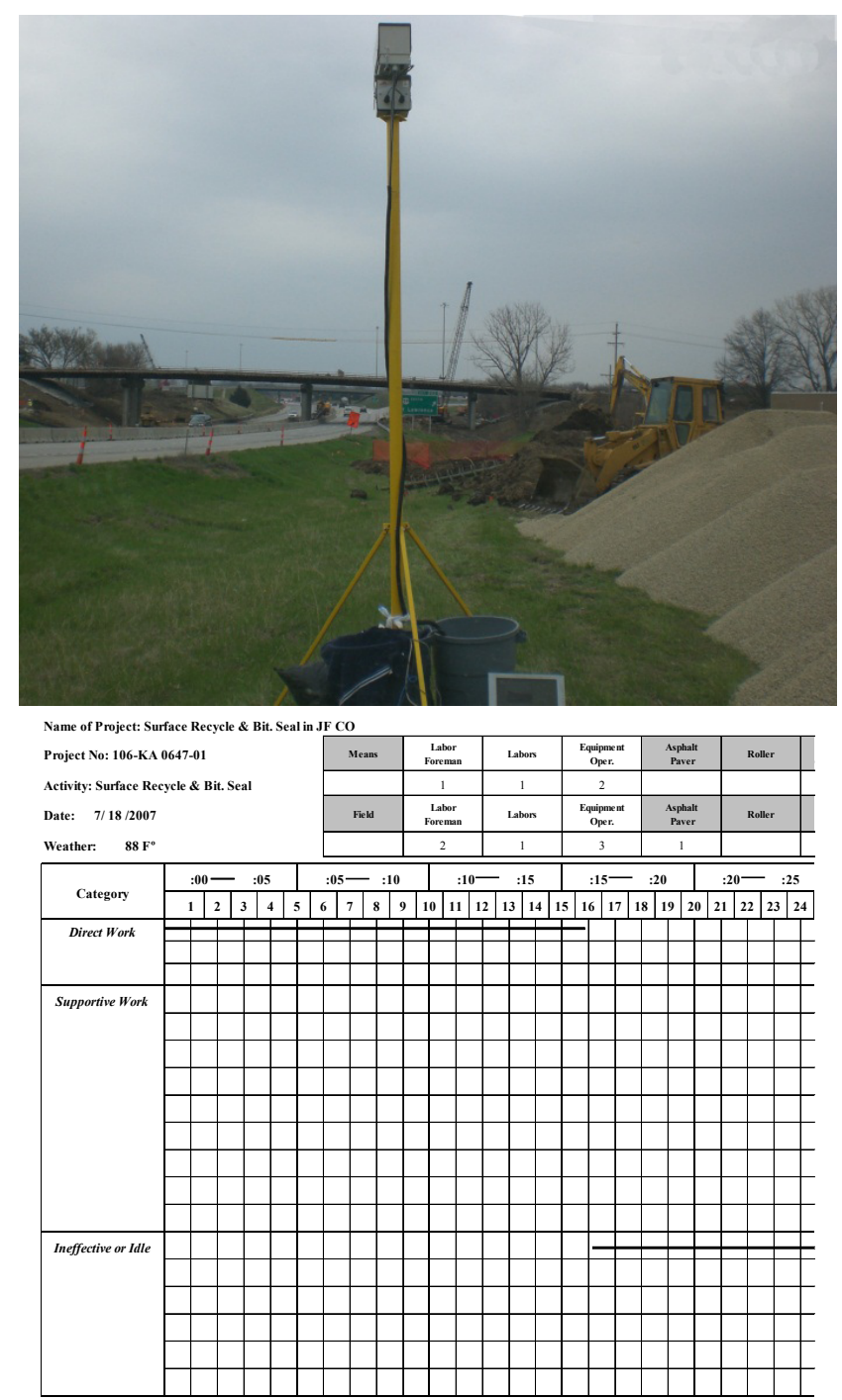

Figure 3: Time study using the WRITE System and Data Collection Form.

\section{Work Breakdown Structure (WBS) for Steel Girder Bridge Construction}

The work breakdown structure (WBS) has been widely used to control the project performance. WBS is defined as "a deliverable-oriented grouping of project elements," which organizes and defines the hierarchical structure of total projects (Jung \& Woo, 2004). It is often used in the complex construction projects to identify project information and improve the efficiency of control processes (Chua \& Godinot, 2006). WBS is often used for integrating the project cost and the project schedule in order to control them. A WBS shows the relationship of all elements of a project, rendering its elements manageable, independent, and measurable. The number of levels relies on the size and complexity of the projects (U.S. Department of Energy, 1997). Prior to this field experiment, the bridge reconstruction project was broken down into four levels for the ease of measurement: level 1 (project), 2 (work zone), 3 (activity), and 4 (operation), as shown in Table 2.

In this research project, labor working status (working ratio and nonworking ratio) of five bridge operations were measured including (1) deck forming, (2) tying rebar, (3) installing 
Seonghoon KIM, Yong BAI. Developing a Model to Enhance Labor Productivity Using Bridge Construction Benchmark Data

PROBLEMS

OF MANAGEMENT

IN THE $21^{\text {st }}$ CENTURY Volume 7, 2013

finisher, (4) backfilling, and (5) placing approach road footing. A total of 66 hours of video tapes were recorded using the WRITE at the project site. However, only a small portion of this data is presented here due to the limitations of paper length. These videos were all taken zoomed-in so that the authors could clearly identify the labor working status for each operation.

Table 2. Work Breakdown Structure (WBS) for Bridge Reconstruction.

\begin{tabular}{llll}
\hline \multirow{2}{*}{$\begin{array}{l}\text { LEVEL 1 } \\
\text { (Project) }\end{array}$} & $\begin{array}{l}\text { LEVEL 2 } \\
\text { (Work Zone) }\end{array}$ & $\begin{array}{l}\text { LEVEL 3 } \\
\text { (Activity) }\end{array}$ & $\begin{array}{l}\text { LEVEL 4 } \\
\text { (Operation) }\end{array}$ \\
\hline & General & Mobilization & Set up Crane \\
\cline { 2 - 4 } & Abutment & Traffic Control & Moving concrete safety barrier \\
\cline { 2 - 4 } & Pier 1 & Demolition & Driving pile \\
\cline { 2 - 4 } & Pier 2 & Excavation & Forming \\
\cline { 2 - 4 } & Pier 3 & Abutment 1 & Structural excavation \\
\cline { 2 - 4 } Steel Girder & Span 1 & Abutment 2 & Tying rebar \\
\cline { 2 - 4 } Bridge & Span 2 & Pier Drill Shafts & Pouring and curing \\
\cline { 2 - 4 } & Span 3 & Pier Columns & Strip and check elevation \\
\cline { 2 - 4 } & Span 4 & Pier Cap & Slope protection, filter fabric and rock \\
\cline { 2 - 4 } & North side & Slope protection & Set bearing devices \\
\cline { 2 - 4 } & South side & Beam Setting & Unload beams \\
\cline { 2 - 4 } & & Deck Forming & Set beams \\
\cline { 2 - 4 } & & Reinforcing Deck & Install diaphragms, bolting, and tightening splice \\
\cline { 2 - 4 } & & Bridge Barrier Rail & Ground splice \\
\cline { 2 - 4 } & & Concrete Barrier & Prepare deck material \\
\cline { 2 - 4 } & & Backfill Abutments & Prepare deck forming \\
\cline { 2 - 4 } & & Overhangs \\
\hline & & Strip \\
\hline & & Place backwall, strip drain, and backfill \\
\hline
\end{tabular}

Benchmarking has been used as a tool to improve efficiency since the early 1980s (Brunso \& Siddiqi, 2003; Yeung, Chan, Chan, Chiang, \& Yang, 2013). According to the previous research projects, the ratio of working time versus the ratio of nonworking time ranges approximately from 50:50 to 60:40 (Hewage \& Ruwanpura, 2006). However, there is no consensus on the acceptable ratio of working time versus ratio of nonworking time in the construction industry because construction projects have different natures such as different types of projects, activities, and operations. To determine the benchmarking data for the five bridge construction operations, a survey form was developed and distributed to four construction professionals who had knowledge on bridge construction. The survey form including two questions is shown in Table 3.

Five construction operations were recorded using the WRITE as a series of color images at a rate of 1 frame per second. These frames were of size $720 \times 480$ pixels with a resolution of 96 dots per inch. In each frame only one construction worker was the focus of the study. The 
ratio of working time for a worker $\mathrm{P}$ is defined as $P(W T)$ and is computed using the following Volume 7, 2013

formula:

$$
P(W T)=\frac{N_{\text {working }}(P)}{\text { Total_Number_of_Frames_for_P }} \quad \text { (1) }
$$

Where, $N_{\text {working }}(P)=$ Number of working frames of the worker $\mathrm{P}$. The ratio of nonworking for a worker $\mathrm{P}$ is defined as $P(N W T)$ and is calculated using the following formula:

Where, $\operatorname{Nworking}(P)=$ Number of working frames of the worker P. The ratio of nonworking for a worker $\mathrm{P}$ is defined as $P(N W T)$ and is calculated using the following formula:

$$
P(N W T)=1-P(W T)
$$

Table 3. Survey Form used for Collecting the Benchmarking Data.

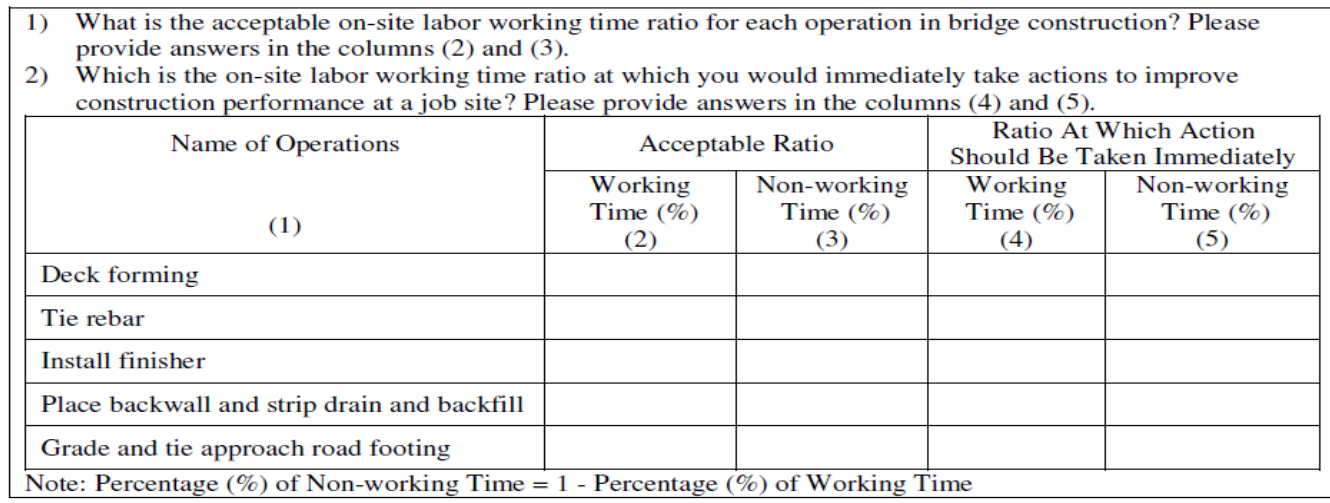

Table 4 shows the acceptable working time ratios provided by four survey participants (P1 to P4). The overall average ratio for working time (WT) was $81 \%$ and overall average ratio for nonworking time (NWT) was 19\%. Tying rebar had the highest nonworking ratio of $21 \%$, while deck forming had the lowest rate of $16 \%$. According to the survey participants, they can accept the working time ratio of at least $79 \%$ for these bridge operations. Table 5 presents the working time ratios at which actions should be immediately taken by a project manager or an engineer to improve on-site construction operations. The overall average ratio for WT was $75 \%$ and overall average for NWT was $25 \%$. Tying rebar had the highest nonworking time rate of $28 \%$, while deck forming had the lowest nonworking time rate of $23 \%$.

Table 6 presents the results of the comparison between the average benchmarking data from the survey and the labor working time ratios determined by the WRITE in a 5-minute segment for each bridge construction operation. For the operation of installing finisher, the nonworking ratio of 24 percent from the WRITE was equal to the ratio at which action should be immediately taken to improve the construction operation by a project manager or an engineer. The rest of the operations had larger working time ratios than the minimum required working time ratios. 
Seonghoon KIM, Yong BAI. Developing a Model to Enhance Labor Productivity Using Bridge Construction Benchmark Data

PROBLEMS

OF MANAGEMENT

IN THE $21^{\text {st }}$ CENTURY Volume 7, 2013

Table 4. Acceptable Working Time Ratios for Five Bridge Construction Operations.

\begin{tabular}{|c|c|c|c|c|c|c|c|c|c|c|}
\hline \multirow{2}{*}{ Operation } & \multicolumn{2}{|c|}{ BRB 1} & \multicolumn{2}{|c|}{ BRB 2} & \multicolumn{4}{|c|}{$\begin{array}{l}\text { A \& M Cohron A \& M Cohron } \\
1\end{array}$} & \multicolumn{2}{|c|}{ Average } \\
\hline & WT & NWT & WT & NWT & WT & NWT & WT & NWT & WT & NWT \\
\hline Deck forming & 85 & 15 & 80 & 20 & 85 & 15 & 85 & 15 & 84 & 16 \\
\hline Tie rebar & 80 & 20 & 75 & 25 & 80 & 20 & 80 & 20 & 79 & 21 \\
\hline Install finisher & 85 & 15 & 75 & 25 & 85 & 15 & 85 & 15 & 82 & 18 \\
\hline $\begin{array}{l}\text { Place backwall and strip drain and } \\
\text { backfill }\end{array}$ & 70 & 30 & 80 & 20 & 85 & 15 & 85 & 15 & 80 & 20 \\
\hline Grade and tie approach road footing & $g 80$ & 20 & 80 & 20 & 85 & 15 & 85 & 15 & 82 & 18 \\
\hline Average & 80 & 20 & 78 & 22 & 84 & 16 & 84 & 16 & 81 & 19 \\
\hline
\end{tabular}

Table 5. Working Time Ratios at Which Actions Should be Taken Immediately.

\begin{tabular}{|c|c|c|c|c|c|c|c|c|c|c|}
\hline \multirow{2}{*}{ Operation } & \multicolumn{2}{|c|}{ BRB 1} & \multicolumn{2}{|c|}{ BRB 2} & \multicolumn{6}{|c|}{ A \& M Cohron 1 A \& M Cohron 2 Average } \\
\hline & WT & NWT & WT & NWT & WT & NWT & WT & NWT & WT & NWT \\
\hline Deck Forming & 75 & 25 & 75 & 25 & 80 & 20 & 80 & 20 & 77 & 23 \\
\hline Tie rebar & 70 & 30 & 70 & 30 & 75 & 25 & 75 & 25 & 72 & 28 \\
\hline Install finisher & 75 & 25 & 70 & 30 & 80 & 20 & 80 & 20 & 76 & 24 \\
\hline $\begin{array}{l}\text { Place backwall and strip drain } \\
\text { and backfill }\end{array}$ & 60 & 40 & 75 & 25 & 80 & 20 & 80 & 20 & 74 & 26 \\
\hline $\begin{array}{l}\text { Grade and tie approach road } \\
\text { footing }\end{array}$ & 70 & 30 & 75 & 25 & 80 & 20 & 80 & 20 & 76 & 24 \\
\hline Average & 70 & 30 & 73 & 27 & 79 & 21 & 79 & 21 & 75 & 25 \\
\hline
\end{tabular}

Note: WT $=$ Working Time (\%); NWT = Nonworking Time $(\%)$ 
Table 6. Comparison between the WRITE System Data and the Benchmark
Data.

\begin{tabular}{|c|c|c|c|c|c|c|}
\hline \multirow{2}{*}{ Operation } & \multicolumn{2}{|c|}{$\begin{array}{l}\text { Acceptable } \\
\text { Ratio }\end{array}$} & \multicolumn{2}{|c|}{$\begin{array}{l}\text { Ratio at which action } \\
\text { should be taken }\end{array}$} & \multicolumn{2}{|c|}{$\begin{array}{l}\text { WRITE } \\
\text { System }\end{array}$} \\
\hline & WT & NWT & WT & NWT & WT & NWT \\
\hline Decking Forming & 84 & 16 & 77 & 23 & 92 & 8 \\
\hline Tie rebar & 79 & 21 & 72 & 28 & 87 & 13 \\
\hline Install finisher & 82 & 18 & 76 & 24 & 76 & 24 \\
\hline $\begin{array}{l}\text { Place backwall and strip drain and } \\
\text { backfill }\end{array}$ & 80 & 20 & 74 & 26 & 96 & 4 \\
\hline $\begin{array}{l}\text { Grade and tie approach road } \\
\text { footing }\end{array}$ & 82 & 18 & 76 & 24 & 89 & 11 \\
\hline Average & 81 & 19 & 75 & 25 & 88 & 12 \\
\hline
\end{tabular}

Note: $\mathrm{WT}=$ Working Time $(\%) ;$ NWT $=$ Nonworking Time $(\%)$

\section{Discussion}

The suggested LWSM model provides a benchmarking framework of real-time monitoring system to determine the efficiency of bridge construction operations for the project management. The literature survey was first conducted. It includes construction productivity measurement methods and theories of WBS and benchmarking. The researchers designed the field experiments including the site selection, layout, procedures, data collection, and benchmark data analysis methods. The survey data analysis from four industry professional involved in the project provided acceptable and unacceptable rate of labor working status and compared with actual efficiency data from the jobsite using the WRITE System. Benchmarks data with real-time communication is a key element for successful completion of projects (Ahuja, Yang, \& Shankar, 2010). With developement of the LWSM Model, the developed model will succefully monitor success or failure of construction operations in real-time basis. The LWSM Module with the WRITE System will be able evaluate jobsite safety, cost, time, and quality in an effective planning and environmental management (Yeung, et al., 2013). By comparing the on-site labor working time ratios from the WRITE with the benchmark ratios, project managers and engineers can take actions to improve on-site construction operations quickly. The results of the implementation demonstrated that the LWSM Model that utilized the WRITE and the benchmark data was an advanced technology and could be implemented to enhance the contractors' capability of managing bridge construction projects for productivity improvements (Ranasinghe, Ruwanpura, \& Liu, 2012).

\section{Conclusions}

To enhance the bridge construction operations, the LWSM Model that utilized the WRITE and the industry benchmark data was developed using advanced technologies. Field implementation of the LWSM Model was successfully conducted to demonstrate how the model was utilized to monitor the on-site labor working status for five bridge construction operations. The success of this research project made several contributions to the advancement of the construction industry. First, it advances the application of wireless technology in bridge construction operations. With wireless technology, images of a construction project site taken by the WRITE could be made available to the project managers and engineers at a remote location in real-time. Thus, data analysis could be performed immediately. Second, comparing 
Seonghoon KIM, Yong BAI. Developing a Model to Enhance Labor Productivity Using Bridge Construction Benchmark Data

PROBLEMS

OF MANAGEMENT

IN THE $21^{\text {st }}$ CENTURY Volume 7, 2013

the labor working status data with the benchmarking data makes it possible for the project managers and engineers to continuously monitor the on-site labor efficiency and take necessary actions immediately to address performance problems, if any. Third, the live images and comparison results can be displayed on a website so that owners, engineers, contractors, and material suppliers are able to share data via the Internet. Thus, communication and coordination will be improved at the construction site. With these advancements, the contractors' capability of managing bridge construction projects will be enhanced.

\section{Acknowledgements}

This research was funded in part by the Transportation Research Institute at The University of Kansas from Grant Number DT0S59-06-G-00047, provided by the Research and Innovative Technology Administration, the U.S. Department of Transportation. Also, this research was funded in part by the National Science Foundation under Grant Number 0741374. The financial support from these agencies is greatly appreciated. The field experimental site was provided by the Kansas Turnpike Authority. Finally, the authors would like to thank Mr. Ken Johnson and Mr. Mike Laird from BRB Contractors, Inc. and Mr. Ray Rinne and Mr. Christopher Rech from A \& M Cohron Inc. for their participation in the survey.

\section{References}

Adrian, J. J. (2004). Construction Productivity: measurement and improvement. Champaign, I.L.: Stipes Publishing L.L.C.

Ahuja, V., Yang, J., \& Shankar, R. (2010). Benchmarking Framework to Measure Extent of ICT Adoption for Building Project Management. [Article]. Journal of Construction Engineering \& Management, 136 (5), 538-545. doi: 10.1061/(asce)co.1943-7862.0000155

Bai, Y., \& Kim, S. H. (2007). Processes and techniques for rapid bridge replacement after extreme events. Transportation Research Record (1991), 54-61.

Barker, R. M., \& Puckett, J. A. (1997). Design of Highway Bridges. New York, N.Y.: Wiley.

Brunso, T. P., \& Siddiqi, K. M. (2003). Using Benchmarks and Metrics to Evaluate Project Delivery of Environmental Restoration Programs. [Article]. Journal of Construction Engineering \& Management, 129 (2), 119.

Chua, D. K. H., \& Godinot, M. (2006). Use of a WBS Matrix to Improve Interface Management in Projects. Journal of Construction Engineering and Management, 132 (1), 67-79.

Fondahl, J. W. (1960). Photographic analysis for construction operations. ASCE -- Proceedings -- Journal of the Construction Division, 86 (C2, Part 1), 9-25.

Gong, J., \& Caldas, C. H. (2010). Computer Vision-Based Video Interpretation Model for Automated Productivity Analysis of Construction Operations. Journal of Computing in Civil Engineering, 24 (3), 252-263.

Hewage, K. N., \& Ruwanpura, J. Y. (2006). Carpentry workers issues and efficiencies related to constuction productivity in commercial construction projects in Alberta. Canadian Journal of Civil Engineering, 33, 1075-1089.

Jung, Y., \& Woo, S. (2004). Flexible Work Breakdown Structure for Integrated Cost and Schedule Control. Journal of Construction Engineering and Management, 130 (5), 616-625.

Noor, I. (1998). Measuring construction labor productivity by daily visits, Cincinnati, OH, USA.

Oglesby, C. H., Parker, H. W., \& Howell, G. A. (1989). Productivity Improvement in Construction. New York, N.Y.: McGraw-Hill, Inc.

Ranasinghe, U., Ruwanpura, J., \& Liu, X. (2012). Streamlining the Construction Productivity Improvement Process with the Proposed Role of a Construction Productivity Improvement Officer. [Article]. Journal of Construction Engineering \& Management, 138 (6), 697-706. doi: 10.1061/(asce) co.1943-7862.0000469

Seonghoon Kim, Y. B., Huan I, and Peddi A,. (2009). Measuring construction productivity using the WRITE System. Paper presented at the 2009 Construction Research Congress, Seattle, WA. 
Thomas, H. R., \& Kramer, D. F. (1988). The Manual of Construction Productivity Measurement and Performance Evaluation: Austin, Tex: Construction Industry Institute.

U.S. Department of Energy. (1997). Cost Codes and the Work Breakdown Structure Retrieved July, 10 2008, from http://www.directives.doe.gov/pdfs/doe/doetext/neword/430/g4301-1chp5.pdf

Yeung, J. F. Y., Chan, A. P. C., Chan, D. W. M., Chiang, Y. H., \& Yang, H. (2013). Developing a Benchmarking Model for Construction Projects in Hong Kong. [Article]. Journal of Construction Engineering \& Management, 139 (6), 705-716. doi: 10.1061/(asce)co.1943-7862.0000622

Advised by Vincentas Lamanauskas, University of Šiauliai, Lithuania

Received: June 29, 2013

Accepted: July 15, 2013

\begin{tabular}{|c|c|}
\hline $\begin{array}{l}\text { Seonghoon Kim } \\
\text { (Corresponding Author) }\end{array}$ & $\begin{array}{l}\text { Ph.D. Assistant Professor, Department of and Civil Engineering and Construc- } \\
\text { tion Management, Georgia Southern University, } 1007 \text { Carruth Bldg, Statesboro, } \\
\text { GA 30461, USA. } \\
\text { E-mail: shkim@georgiasouthern.edu } \\
\text { Website: http://ceit.georgiasouthern.edu/civil-engineering/cm/faculty/ }\end{array}$ \\
\hline Yong Bai & $\begin{array}{l}\text { Ph.D. Chair and Professor, Department of Construction Management and } \\
\text { Engineering, North Dakota State University, P. O. Box 6050, Dept. 2475, Fargo, } \\
\text { ND 58108-6050, USA. } \\
\text { E-mail: yong.bai@ndsu.edu } \\
\text { Website: http://www.yongbai.org/ }\end{array}$ \\
\hline
\end{tabular}

